\title{
Avaliação da eficiência do citrato de tamoxifeno na inversão sexual de tilápia do Nilo (Oreochromis niloticus)
}

\section{Evaluation of tamoxifen citrate efficiency on sexual inversion of Nile tilapia (Oreochromis niloticus)}

\author{
Marco Antonio Zanoni ${ }^{1 *}$; Fabiano Gonçalvez Costa ${ }^{1}$; Aline Nazareno ${ }^{2}$; \\ Mauro Caetano Filho ${ }^{3}$; Carlos Antonio Lopes de Oliveira ${ }^{4}$; Ricardo Pereira Ribeiro ${ }^{4}$
}

\section{Resumo}

O experimento foi realizado com o objetivo de avaliar a influência do tamoxifeno na inversão sexual de larvas de tilápia a partir dos dois dias de vida. Os animais foram distribuídos em um delineamento experimental de cinco tratamentos e três repetições, recebendo dietas com diferentes quantidades de tamoxifeno: $0,25,50,75$ e $100 \mathrm{mg} \mathrm{kg}^{-1}$ de ração. Após 28 dias de tratamento, as larvas restantes em cada tratamento foram contadas e transferidas para caixas de água de $500 \mathrm{~L}$ onde receberam ração comercial com $28 \%$ de proteína bruta por 60 dias. Após este período, os alevinos foram sexados pelo método "squash". A sobrevivência 75,5 $\pm 5,74$; $73 \pm 4,76 ; 66 \pm 11,19 ; 76,5 \pm 4,12 ; 75 \pm 3,46 \%$ e a porcentagem média de indivíduos machos $62,5 \pm 5 ; 70 \pm$ 8,$1 ; 60 \pm 8,2 ; 70 \pm 0,0 ; 62,5 \pm 9,5 \%$ para os tratamentos $0,25,50,75$ e $100 \mathrm{mg}$ de tamoxifeno $\mathrm{kg}^{-1}$ de ração, respectivamente, não apresentaram diferenças estatísticas significativas. O número de gônadas presentes em cada indivíduo apresentou redução significativa, nos tratamentos com 75 e $100 \mathrm{mg}$ de tamoxifeno $(89,3 \pm 0,527$ e 79,3 $\pm 0,378 \%$ ) quando comparado com os tratamentos 0,25 e $50 \mathrm{mg}$ de tamoxifeno $(98,9 \pm 1,0 ; 97,6 \pm 1,0$ e 94,5 $\pm 1,0 \%$, respectivamente), a estrutura histológica das gônadas femininas não apresentou diferenças e os ovários em todos os tratamentos apresentaram ovócitos bem definidos e em vários estádios de maturação. Palavras-chave: Receptor de estrógeno, monossexo, perturbador endócrino, peixe

\begin{abstract}
The experiment was conducted to evaluate the influence of tamoxifen on sexual inversion of Nile tilapia larvae from two days of life, the experimental desing was compounded of five treatments and three replicates, and fish were fed diets with different amounts of tamoxifen: 0, 25, 50, 75 and $100 \mathrm{mg} \mathrm{kg}^{-1}$ of feed. After 28 days of treatment, larvae were counted and transferred to water tanks of 500 liters and then which were fed with a diet containing $28 \%$ crude protein for more 60 days. After this period the fry were sexed by the "squash". The survival $75.5 \pm 5.74,73 \pm 4.76,66 \pm 11.19,76.5 \pm 4.12,75 \pm 3.46$ and average percentage of male individuals $62.5 \pm 5,70 \pm 8.1,60 \pm 8.2,70 \pm 0.0,62.5 \pm 9.5$ for treatments 0 , $25,50,75$ and $100 \mathrm{mg}$ of tamoxifenk $\mathrm{g}^{-1}$ diet, respectively, showed no statistically significant differences $(\mathrm{p}<0,05)$. The number of gonads in each fish experienced a significant reduction in the treatments with 75 and $100 \mathrm{mg}$ of tamoxifen (89.3 and $79.3 \pm 0.527 \pm 0.378)$ when compared with treatments 0,25 and $50 \mathrm{mg}$ of tamoxifen $(98,9 \pm 1.0,97.6 \pm 1.0$ and $94.5 \pm 1.0$, respectively), the histological structure of female gonads did not differ and ovaries in all treatments showed well-defined and oocytes at several stages of maturation.
\end{abstract}

Key words: Estrogen receptor, monosex, endocrine disruptor, fish

\footnotetext{
${ }^{1}$ Profs., Setor de Biologia, Centro de Ciências Biológicas, Universidade Estadual Norte do Paraná, UENP, Campus Luiz Meneghel, Bandeirantes, PR. E-mail: zanoni@uenp.edu.br; fabianocosta@uenp.edu.br

2 Discente do Curso de Graduação em Ciências Biológicas, UENP, Bandeirantes, PR. E-mail: alinenaz@hotmail.com

${ }^{3}$ Biólogo responsável pela Estação de Piscicultura, Centro de Ciências Biológicas, UENP, Londrina, PR. E-mail: mcaetanofilho@ hotmail.com

${ }^{4}$ Profs., Dept ${ }^{\mathrm{o}}$ de Zootecnia, da Universidade Estadual de Maringá, UEM, Maringá, PR. E-mail: caloliveira@uem.br; rpribeiro@ uem.br

* Autor para correspondência
} 


\section{Introdução}

O cultivo de peixes monossexo é desejável em diversos sistemas de produção aquícola, sendo que os benefícios de sua utilização incluem a maior taxa de crescimento, eliminação de reprodução, redução do comportamento territorial, redução da variação no tamanho de despesca e redução do risco de impacto ambiental resultante da fuga de espécies exóticas (BEARDMORE; MAIR; LEWIS, 2001).

Atualmente, o método mais prático e eficiente para a obtenção de lotes monossexos de tilápias é pela incorporação de hormônios esteróides à ração, sendo o 17 a-metiltestosterona o mais utilizado (PHELPS; POPMA, 2000). A utilização deste esteróide na produção de monossexo de peixes, já foi questionada no passado. Sobre isto, Johnstone, Macintosh e Wright (1983) afirmaram que seu uso preocupa pelos resíduos que podem permanecer nos peixes tratados e que podem ser transferidos ao consumidor, ou liberados no ambiente, contudo Zanardi et al. (2011) observaram que em alevinos tratados 17 a-metiltestosterona, a quantidade deste andrógeno, 30 dias após o término do período de reversão, era semelhante aos níveis de produção endógena.

$\mathrm{Na}$ maioria dos vertebrados, os embriões têm gônada bipotencial que pode desenvolver um ovário ou um testículo. As gônadas de peixes em geral são muito instáveis em relação à determinação do sexo, sendo a interação gene/ambiente, determinante para o desenvolvimento sexual futuro (DEVLIN; NAGAHAMA, 2002; PIFERRER; GUIGEN, 2008).

A atuação dos estrógenos na diferenciação ovariana está firmemente estabelecida na maioria dos vertebrados, entre os quais: aves (SMITH; SINCLAIR, 2004), répteis (PIEAU; DORIZZI, 2004), anfíbios (HAYES, 1998; MIYATA; KUBO, 2000) e peixe (DEVLIN; NAGAHAMA, 2002). Nos peixes é possível comprovar a importância dos estrógenos pela presença de enzimas responsáveis pela esteroidogênese ou pelo estrógeno produzido na época da diferenciação sexual (NAKAMURA;
BHANDARI; HIGA, 2003; BHANDARI et al., 2006). Outra comprovação é a constatação de que o tratamento com estrógeno exógeno feminiza sexualmente peixes indiferenciados (PIFERRER, 2001).

A ação do estrógeno é mediada, pelo menos, por dois receptores, denominados $\alpha(\mathrm{RE} \alpha)$ e $\beta(\mathrm{RE} \beta)$, que são membros da família de receptores nucleares. A ligação entre o receptor e o estrógeno regula a expressão de genes diretamente, pela sua vinculação a um ciselemento, denominado elemento estrogênio responsivo (EER) ou indiretamente por meio da interação com outros fatores de transcrição específica (MATTHEWS; GUSTAFSSON, 2003). Nos peixes teleósteos, a existência de dois subtipos de RE foi confirmada em Oreochromis niloticus (CHANG et al., 1999); Sparus aurata (SOCORRO et al., 2000); Ictalurus punctatus (XIA et al., 1999; 2000); Paralichthys olivaceus (KITANO et al., 2006).

O tamoxifeno é um composto derivado do trifeniletileno, amplamente utilizado no tratamento de câncer de mama primário e recorrente (CARLSON, 1997), sendo facilmente absorvido via oral, atingindo níveis plasmáticos máximos quatro a sete horas após a ingestão. Este fármaco, que possui solubilidade de $0,01 \%$ em meio aquoso (BÉRUBÉ et al., 2006), mostra duas fases de eliminação tendo a primeira fase uma meia-vida de 7 a $14 \mathrm{~h}$, e a segunda de quatro a 11 dias (GRAHAME-SMITH; ARONSON, 2002).

A ação farmacêutica do tamoxifeno é a de um antagonista do RE, formando um complexo relativamente estável com o receptor $17 \beta$-estradiol e, assim, reduzindo o número de receptores disponíveis (JORDAN et al., 1977). Estudos recentes demonstraram que o tamoxifeno também tem propriedades agonísticas do estrogênio, dependendo da espécie e tecido (OSBORNE; ELLEDGE; FUQUA, 1996). Pela sua ação múltipla, o tamoxifeno é referido como um modulador do RE (MUELLER; KORACH, 2001).

Efeitos do tamoxifeno sobre a diferenciação do 
sexo gonadal foram relatados em aves (KOO et al., 1985) e em répteis (DORIZZI et al., 1991) com determinação do sexo dependente da temperatura. Nos peixes teleósteos, a ação do tamoxifeno pode variar dependendo da espécie; Guiguen et al. (1999) não conseguiram promover a inversão sexual da truta (Oncorhynchus mykiss) e tilápia (Oreochromis niloticus), usando doses de 5 e $20 \mathrm{mg} \mathrm{kg}^{-1}$ de ração para a truta e $25 \mathrm{mg} \mathrm{kg}^{-1}$ de ração para a tilápia, já Hines e Watts (1995) relatam resultados positivos na inversão sexual de híbridos de tilápias $(O$. niloticus $\mathrm{x}$ O. aureus) na dosagem de $100 \mathrm{mg} / \mathrm{Kg}$ de ração. No linguado japonês, o tamoxifeno foi capaz de induzir a masculinização de peixes indiferenciados, sendo o efeito dependente da dose e capaz de atuar de forma eficiente nos receptores de estrógeno do tipo $\alpha$ e $\beta$ (KITANO et al., 2007).

Esse experimento avaliou se a inversão sexual da tilápia do Nilo (O. niloticus) pode ser obtida pela ação do citrato de tamoxifeno, adicionado à dieta em diferentes dosagens.

\section{Material e Métodos}

O experimento foi realizado no Laboratório de Reprodução de Espécies Nativas da Estação de Piscicultura da Universidade Estadual de Londrina (Epuel), no período de 09 de junho a 06 de agosto de 2011. A sifonagem dos resíduos e das fezes, bem como a renovação da água, foram constantes em todas as unidades experimentais. A temperatura foi mantida em $26^{\circ} \mathrm{C}$ com o auxílio de termostatos e aquecedores elétricos.

Foram realizadas semanalmente coletas de amostras de água, para a avaliação das seguintes variáveis de qualidade de água: $\mathrm{pH}$ (potenciômetro digital), oxigênio dissolvido $\left(\mathrm{mgL}^{-1}\right)$ e temperatura $\left({ }^{\circ} \mathrm{C}\right)$ (oxímetro YSI - Yellow Spring Instruments), alcalinidade $\mathrm{CaCO}_{3}\left(\mathrm{mgL}^{-1}\right)$ (titulação) e amônia $\left(\mathrm{mgL}^{-1}\right)$ (colorimétrico), utilizando a metodologia de Golterman, Clymo e Ohnstad (1978).

As larvas de tilápia do Nilo (O. niloticus), variedade Supreme com dois dias pós- eclosão, utilizadas nesse experimento foram provenientes da Piscicultura Aquabel (Rolândia, Estado do Paraná). Após serem transportadas até a Epuel, as larvas foram separadas ao acaso em 20 grupos de 50 animais, e distribuídas nas unidades experimentais, as quais eram constituídas por recipientes plásticos com volume de 40 L. Após um dia de aclimatação, as larvas passaram a receber quatro vezes ao dia por um período de 28 dias, as dietas experimentais, as quais foram oferecidas até a saciação, contendo 0, 25, 50, 75 e $100 \mathrm{mg}$ de Citrato de Tamoxifeno por quilograma de ração com $42 \%$ de proteína. O Citrato de Tamoxifeno foi pesado em balança de precisão, macerado em cadinho e diluído em 250 $\mathrm{mL}$ de álcool e só então misturado à ração. A dieta controle foi preparada misturando-se a $1,0 \mathrm{~kg}$ de ração e $250 \mathrm{~mL}$ de álcool. Após a evaporação do álcool, as rações foram empacotadas e guardadas em um freezer a $-4^{\circ} \mathrm{C}$.

Uma amostra de 15 indivíduos foi retirada ao acaso antes de serem distribuídas nas unidades experimentais para biometria. Foram realizadas biometrias com amostras de cinco indivíduos de cada tratamento no $14^{\circ}$ e $28^{\circ}$ dia. Nas três coletas, os animais foram insensibilizados com benzocaína (3 g $100 \mathrm{~mL}^{-1}$ de álcool), sacrificados em álcool 70, e armazenados em frascos de vidro identificados por tratamento. Posteriormente, as larvas foram medidas com o auxílio de um paquímetro digital, secas em papel toalha e pesadas em balança analítica. Para o cálculo de sobrevivência, as larvas sacrificadas durante as biometrias não foram consideradas.

Após essa fase, as larvas foram transferidas para 15 caixas d'água plásticas de $500 \mathrm{~L}$. A temperatura, durante essa fase, foi mantida em $26^{\circ} \mathrm{C}$ com o auxílio de um aquecedor. $\mathrm{O}$ manejo alimentar foi realizado duas vezes ao dia, oferecendo-se ração comercial sem a adição de tamoxifeno, com $28 \%$ de proteína bruta, até a saciação. Assim que os peixes cessaram a alimentação na segunda vez que se ofereceu o alimento, os resíduos acumulados no fundo das caixas plásticas foram sinfonados. 
Após 60 dias, dez indivíduos de cada repetição foram escolhidos aleatoriamente, anestesiados com o auxílio de benzocaína, sacrificados em solução Bouin, armazenados em vidros com identificação e, posteriormente, colocados em álcool 70. Para a análise da porcentagem de inversão sexual, os alevinos tiveram seu peso e medidas tomados com o auxílio de uma balança de precisão e um paquímetro digital. A cavidade abdominal foi aberta com o auxílio de tesoura e pinça, e as gônadas avaliadas quanto ao número presente em cada animal. Após a determinação do número de gônadas presentes, essas foram retiradas, pesadas e transferidas para uma lâmina, onde foram coradas com acetatocarmim, prensadas com o auxílio de uma lamínula (Squash) e avaliadas em microscopia óptica em aumento de 40 vezes.

Para a análise histológica das gônadas, dezindivíduos de cada tratamento foram anestesiados com o auxílio de benzocaína e sacrificados, suas gônadas retiradas e fixadas em solução de Bouin. Após $12 \mathrm{~h}$ no fixador, as gônadas foram lavadas em água e desidratadas em uma bateria de álcool e diafanizadas em xilol, incluídas em paraplast e os blocos foram cortados na espessura de 5 $\mu \mathrm{m}$. Os cortes foram corados com hematoxilina-eosina e observados em microscopia de luz.

Os dados obtidos de sobrevivência, porcentagem de machos e número de gônadas, por apresentarem uma caracterização binária, em que se verifica a sobrevivência ou a morte, a ocorrência de machos ou fêmeas e a presença de uma ou de duas gônadas, foram submetidos a análises estatísticas utilizando a metodologia de modelos lineares generalizados, implementado no PROC GENMOD do sistema computacional SAS. Para as variáveis, considerouse a distribuição binomial com função ligação logit. Ajustou-se uma regressão logística da percentagem de indivíduos com ocorrência de uma ou duas gônadas nos diferentes tratamentos.

Para avaliar o ganho em peso dos animais submetidos aos diferentes tratamentos nesse experimento, os resultados de peso final obtidos na última biometria foram submetidos ao teste de análise de variância.

\section{Resultados e Discussão}

Os parâmetros físicos e químicos da água, no interior das unidades experimentais foram: temperatura da água $26 \pm 1,5^{\circ} \mathrm{C}$; oxigênio dissolvido $\left(\mathrm{mg} \mathrm{L}^{-1}\right)$ 4,8 $\pm 0,5 ; \mathrm{pH} 6,9 \pm 0,2 ;$ alcalinidade total 60 $\mathrm{mg} \mathrm{L}^{-1}$ e amônia total $<0,5 \mathrm{ppm}$. Esses valores, de acordo com Boyd (1990) e Popma e Lovshin (1996), estão dentro do considerado como o recomendado para a aquicultura e na faixa de conforto para a espécie estudada.

Neste experimento na biometria inicial, os indivíduos amostrados (dois dias de vida) apresentavam os seguintes valores médios de peso e comprimento total: $0,0134 \pm 0,00029$ g e $10,542 \pm 0,41 \mathrm{~mm}$, respectivamente. Este valor de comprimento médio inicial é inferior ao considerado por Bombardelli e Hayashi (2005), que após testarem a inversão sexual de Oreochromis niloticus utilizando banhos de imersão com 17 $\alpha$-metiltestosterona, em larvas que mediam de 9,10 a $13,30 \mathrm{~mm}$, obtiveram melhores resultados de masculinização utilizando larvas de $13,30 \mathrm{~mm}$, sugerindo ser este o tamanho de início do período ontogênico de maior sensibilidade à ação hormonal, nessa espécie.

As médias de ganho em peso obtidas nas biometrias das larvas de tilápia do Nilo submetidas aos diferentes tratamentos foram utilizadas na curva de ganho em peso (Figura 1).

Os valores de peso final das larvas submetidas aos tratamentos $0,25,50,75$ e $100 \mathrm{mg}$ de citrato de tamoxifeno $\mathrm{kg}^{-1}$ de ração foram, respectivamente, $0,121 \pm 0,0300 ; 0,144 \pm 0,038$; $0,173 \pm 0,0402 ; 0,112 \pm 0,040$ e $0,178 \pm 0,061$ g e não apresentaram diferenças estatísticas significativas. O coeficiente de variação de 57,15\% demonstra crescimento heterogêneo, e segundo Volpato, Frioli e Carrieri (1989), o crescimento heterogêneo entre larvas e alevinos de tilápia, é uma característica comum e está relacionada ao estabelecimento de hierarquias entre os peixes. 
Figura 1. Curva de ganho em peso de larvas de tilápia do Nilo variedade Supreme, submetidas a tratamentos com dietas contendo diferentes quantidades de citrato de tamoxifeno $\left(0,25,50,75\right.$ e $100 \mathrm{mgkg}^{-1}$ de ração), por um período de 28 dias.

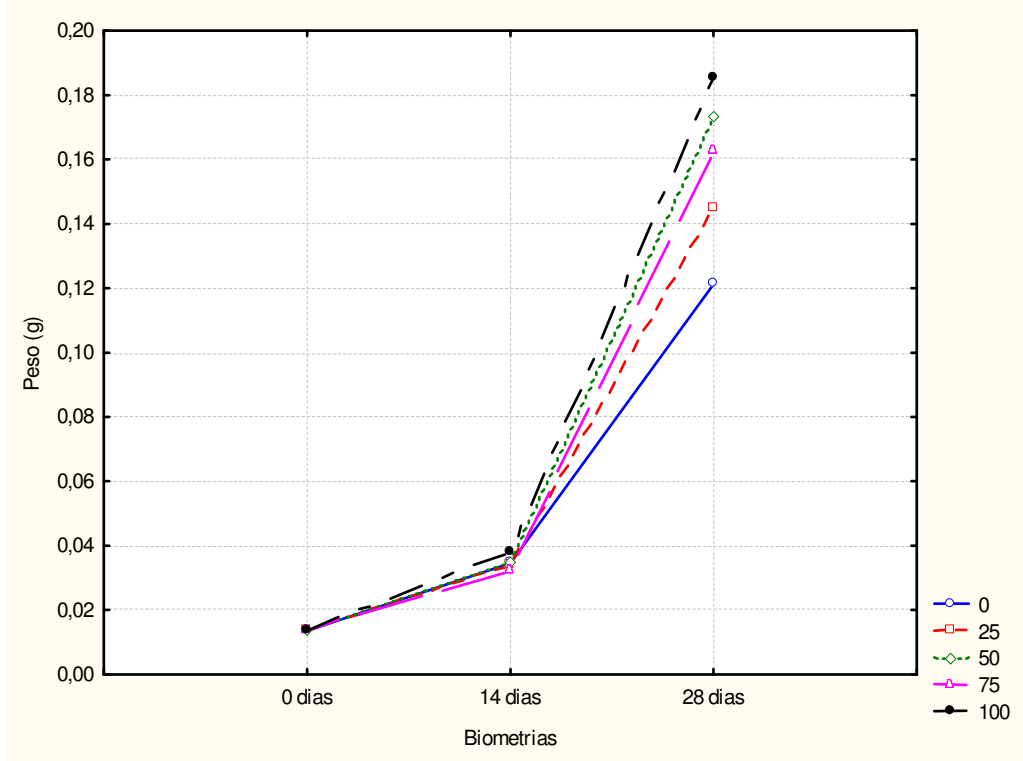

Fonte: Elaboração dos autores.

Os valores encontrados para sobrevivência foram 75,5 $\pm 5,74 ; 73 \pm 4,76 ; 66 \pm 11,19 ; 76,5 \pm$ 4,$12 ; 75 \pm 3,46 \%$ para os tratamentos $0,25,50,75$ e $100 \mathrm{mg}$ de citrato de tamoxifeno $\mathrm{kg}^{-1}$ de ração, respectivamente. A análise estatística demonstrou não haver diferenças estatísticas entre as médias da porcentagem neste experimento, as quais são menores que as obtidas por Hines e Watts (1995) que encontraram valores de sobrevivência entre 84 a $90 \%$ de larvas de tilápia (O. niloticus x O. aureus) alimentadas com dietas contendo tamoxifeno, os autores ainda relatam que não encontraram diferenças significativas de sobrevivência. Segundo Cruz e Mair (1994), a sobrevivência está relacionada a fatores sociais de dominância já que indivíduos dominantes dentro de uma população podem consumir mais alimentos e crescer mais rápido, deixando menos alimento para os indivíduos submissos que têm menor crescimento e que, portanto se tornam vulneráveis ao canibalismo e a morte por inanição.

As médias de sobrevivência obtidas nesse experimento variaram entre $66 \pm 11,19$ a $76,5 \pm 4,12 \%$, as quais estão próximas às consideradas ideais por Popma e Green (1990) que, para larvas com 28 dias mantidas em ambientes externos, variam entre 70 a $90 \%$. No entanto, o presente experimento foi realizado em condições controladas em tanques internos, corroborando os resultados encontrados por Phelps e Popma (2000).

Os resultados de inversão sexual: $62,5 \pm 5 ; 70 \pm$ 8,$1 ; 60 \pm 8,2 ; 70 \pm 0,0 ; 62,5 \pm 9,5 \%$ para os tratamentos $0,25,50,75$ e $100 \mathrm{mg}$ de citrato de tamoxifeno $\mathrm{kg}^{-1}$ ração, respectivamente, não apresentaram diferenças estatísticas $(p<0,05)$, o que difere dos resultados obtidos por Hines e Watts (1995) que estudando a ação de substâncias não-esteróides (citrato de tamoxifeno) na inversão sexual de híbridos de tilápia (Oreochromis niloticus x O. aureus), obtiveram resultados que variaram de 66 a 100\% de inversão sexual das larvas alimentadas com 5 a $100 \mathrm{mg} \mathrm{kg}^{-1} \mathrm{de}$ tamoxifeno presente na dieta. Contudo, este resultado de $100 \%$ machos do tratamento com $100 \mathrm{mg}$ de citrato de tamoxifeno por quilograma de ração obtido pelos autores Hines e Watts (1995), pode ser explicado pelo cruzamento interespecífico de fêmea XX de 
O. niloticus com machos $\mathrm{ZZ}$ de $O$. aureus, o que resultaria, segundo Beardmore, Mair e Lewis (2001) em uma progênie com fenótipo $100 \%$ macho.

A não obtenção de valores elevados de indivíduos machos nos tratamentos com maior quantidade de citrato de tamoxifeno neste experimento demonstrou haver uma diferença de sensibilidade na ação deste fármaco em $O$. niloticus, sugerindo que a eficiência na formação do complexo tamoxifeno/receptores de estrogênio nos peixes é dependente de fatores ainda não conhecidos. Esta afirmação é corroborada pelos resultados obtidos por Kitano et al. (2007), que diferentemente dos resultados obtidos neste experimento com tilápias, observaram que o tamoxifeno foi capaz de promover a inversão sexual do linguado (Paralichthys olivaceus) bloqueando o receptores de estrógeno $\alpha$ e $\beta$ e por Piferrer e Guiguen (2008) que afirmaram que os resultados de inversão sexual com tamoxifeno não são constantes quando diferentes espécies são comparadas e por vezes, nem mesmo entre os tecidos de uma mesma espécie, ou ainda, entre diferentes fases de desenvolvimento do mesmo tecido.

As fotomicrografias citológicas obtidas pela metodologia squash das gônadas podem ser observadas na figura 2. $\mathrm{Na}$ imagem $\mathrm{A}$ pode ser observado o tecido ováriano em um microscópio de luz com objetiva de 40 vezes, demonstrando a presença de ovócitos com seus núcleos evidentes e seus respectivos limites celulares, enquanto que na imagem $\mathrm{B}$, os testículos ainda indiferenciados, apresentam espermatogônias, porém, sem túbulos seminíferos distintos.

A ação do tamoxifeno, segundo Nagahama (2005), é a de antagonista do receptor de estrógeno em fêmeas genéticas e, portanto altera o fenótipo fêmea para macho, o que reforça a idéia de que o estrógeno endógeno e seus receptores têm papel importante na diferenciação dos ovários de tilápia. Contudo, neste experimento, o tamoxifeno não foi efetivo na inversão sexual de tilápias.

Figura 2. Fotomicrografia de ovário de tilápia do Nilo (imagem A) coradas com acetato carmim, ovócitos com núcleos evidentes (seta) e seus limites celulares (cabeça de seta). Testículo (imagem B) em fase inicial de desenvolvimento testicular e com a presença de espermatogônias (seta).

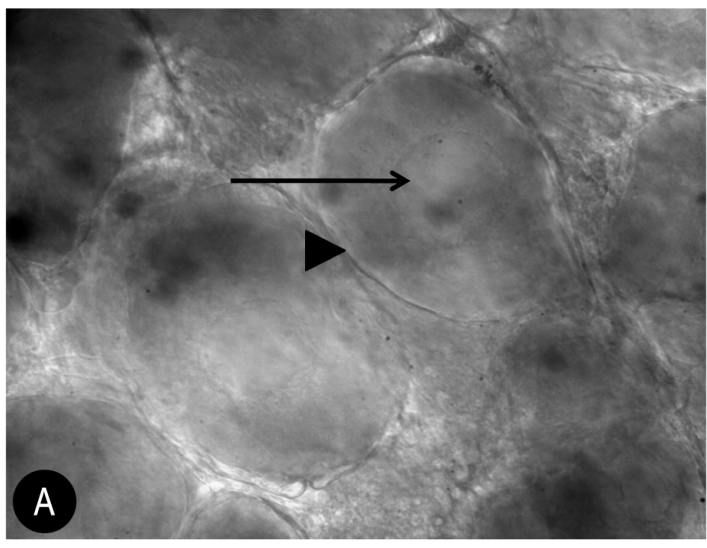

Fonte: Elaboração dos autores.

Experimentos realizados por Guiguen et al. (1999) também não obtiveram resultados positivos na inversão sexual de Trutas (Oncorhynchus mykiss) utilizando 5 e $20 \mathrm{mg}$ de tamoxifeno por quilograma de ração e também na Tilápia (Oreochromis

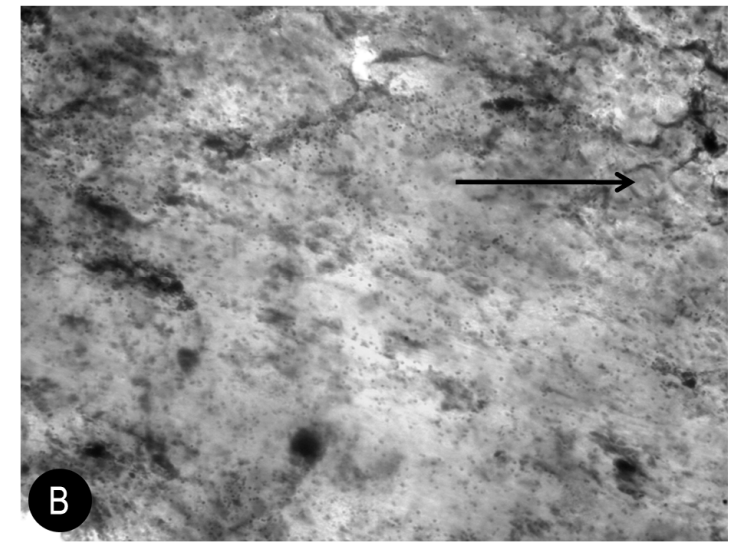

niloticus) na quantidade de $25 \mathrm{mg} \mathrm{kg}^{-1}$ de ração. Os autores sugeriram que a possível explicação para estes resultados pode ser por um efeito agonista do tamoxifeno, uma vez que quando formado o complexo tamoxifeno-receptor de estrógeno, 
o receptor pode permanecer parcialmente ativo e, portanto, capaz de transmitir tanto os efeitos estrogênicos como os antiestrogênicos (JORDAN, 1977). Esse efeito estrogênico foi comprovado por Navarro-Martín, Bláquez e Piferrer (2009) que em estudos realizados com Dicentrarchus labrax alimentados com dietas, contendo $100 \mathrm{mg}$ citrato de tamoxifeno, obtiveram $100 \%$ de fêmeas.

A quantidade de gônadas pares presentes em cada animal nos tratamentos que utilizaram 75 e $100 \mathrm{mg}$ de citrato de tamoxifeno $\mathrm{kg}^{-1}$ de ração $(89,3 \pm 0,527 \mathrm{e}$ $79,3 \pm 0,378 \%$ ) sofreu redução significativa quando comparada aos tratamentos 0,25 e $50 \mathrm{mg}(98,9 \pm 1,0$; $97,6 \pm 1,0$ e $94,5 \pm 1,0 \%$, respectivamente) (Figura 3 ).

Segundo Hines e Watts (1995), o uso de altas dosagens (acima de $150 \mathrm{mg}$ ) de citrato de tamoxifeno, influencia o desenvolvimento das gônadas, aumentando a incidência de anormalidades, e também causando problemas na formação óssea do animal.
O citrato de tamoxifeno é considerado um desregulador endócrino, que atua ligando-se aos receptores de estrógeno nas células do ovário e do cérebro, competindo ou mimetizando a ação do hormônio estrogênio, estimulando a ação (agonista) ou bloqueando e reduzindo a ação do efeito biológico (antagonista) e, segundo Sharpe et al. (2004), este processo pode desregular a síntese hormonal, transporte e metabolismo, resultando em mudanças organizacional e funcional do órgão alvo. Neste experimento, apesar de haver uma redução significativa no número de gônadas presentes nos indivíduos do tratamento com 75 e $100 \mathrm{mg}$ de citrato de tamoxifeno $\mathrm{kg}^{-1}$ de ração, a análise dos cortes histológicos (Figura 4) demonstrou não haver alterações estruturais na histologia nos ovários nos diferentes tratamentos, os quais apresentavam ovócitos em diferentes estádios de maturação com núcleos e citoplasma evidentes demonstrando desenvolvimento normal.

Figura 3. Curva e reta de regressão do número de gônadas pares observadas em alevinos de tilápia do Nilo submetidas a dietas contendo diferentes quantidades de citrato de tamoxifeno.

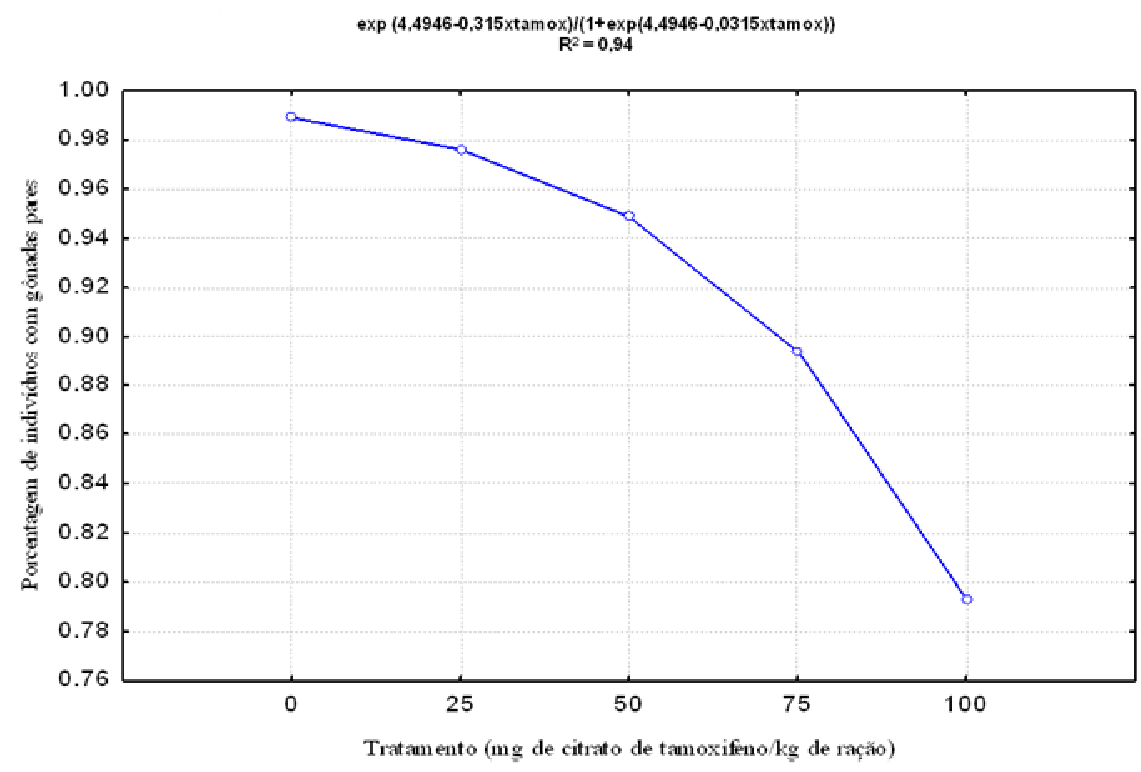

Fonte: Elaboração dos autores. 
Figura 4. Micrografias de gônadas de tilápia do Nilo, coradas com hematoxilina-eosina e observadas em aumento de 40 vezes, submetidas a diferentes dietas contendo citrato de tamoxifeno. Os ovários apresentam ovócitos normais em diferentes estádios de maturação.
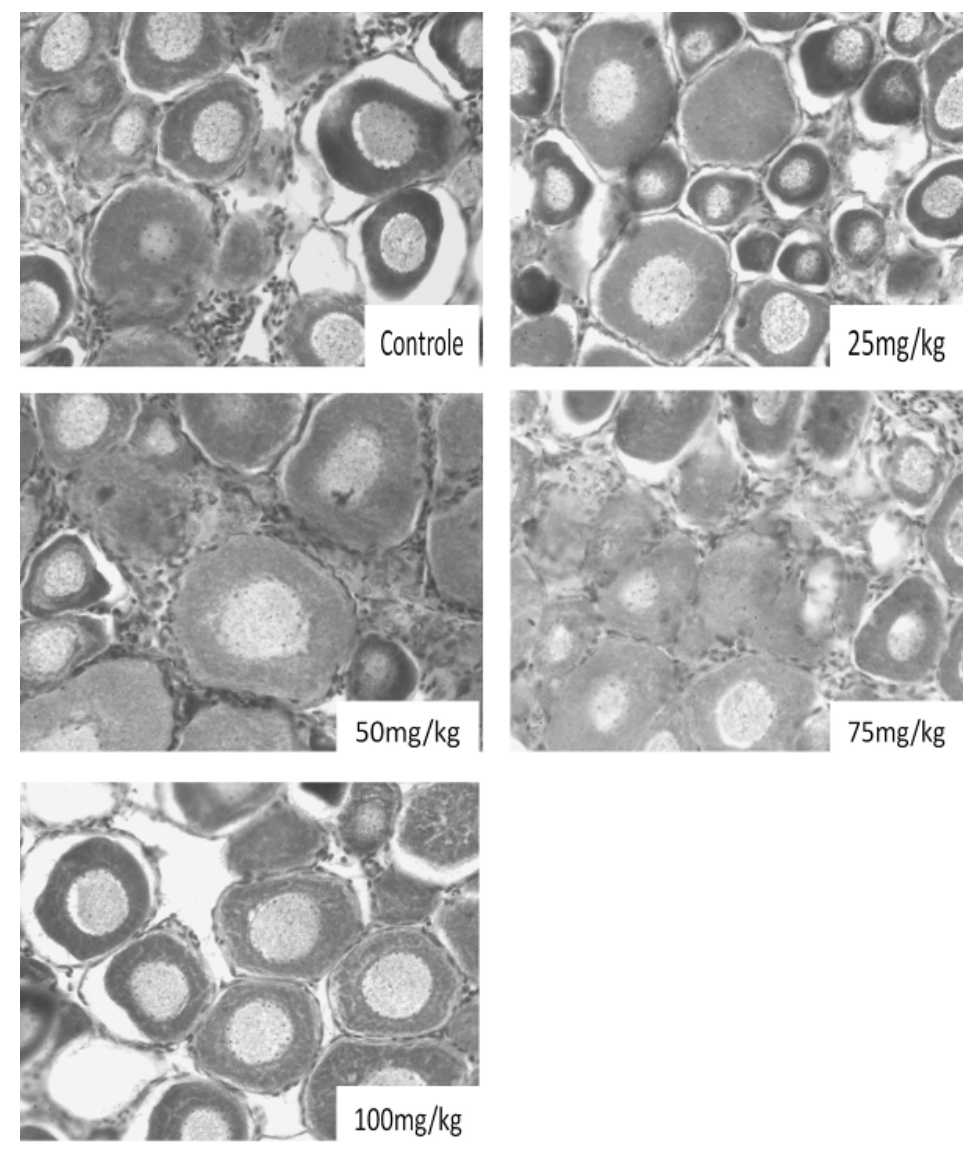

Fonte: Elaboração dos autores.

\section{Conclusão}

Pelos resultados pode-se concluir que o citrato de tamoxifeno não promoveu a inversão sexual de tilápias. A redução do número de gônadas em indivíduos submetidos aos tratamentos com 75 e $100 \mathrm{mg}$ de citrato de tamoxifeno aponta para a possibilidade do fármaco ser utilizado na produção de animais estéreis. A realização de mais estudos é necessária para esclarecer essa possibilidade.

\section{Referências}

BEARDMORE, J. A.; MAIR, G. C.; LEWIS, R. I. Monosex male production in finfish as exemplified by tilapia: applications, problems, and prospects.

Aquaculture, Amsterdam, v. 197, n. 1-4, p. 283-301, 2001.

BÉRUBÉ, G.; RABOUIN, D.; PERRON, V.; N'ZEMBA, B.; GAUDREAULT, R. C.; PARENT, S.; ASSELIN, E. Synthesis of unique $17 \alpha$-estradiol homo-dimers, estrogen receptors binding affinity evaluation and cytocidal activity on breast, intestinal and skin cancer cell lines. Steroids, Santa Barbara, v. 71, n. 10, p. 911-921, 2006.

BHANDARI, R. K.; NAKAMURA, M.; KOBAYASHI, T.; NAGAHAMA, Y. Suppression of steroidogenic enzyme expression during androgen induced sex reversal in Nile tilapia (Oreochromis niloticus). General and Comparative Endocrinology, London, v. 145, n. 1, p. 2024, 2006.

BOMBARDELLI, R. A.; HAYASHI, C. Masculinização de larvas de tilápia do Nilo (Oreochromis niloticusL.) a partir de banhos de imersão com 17alfa-metiltestosterona. 
Revista Brasileira de Zootecnia, Viçosa, MG, v. 34, n. 2, p. 365-372, 2005.

BOYD, C. Water quality in ponds for aquaculture. London: Birmingham, 1990. 482 p.

CARLSON, R.W. Scientific review of tamoxifen: overview from a medical oncologist. Seminars in Oncology, New York, v. 24, n. 1, p. 151-157, 1997. Suplemento.

CHANG, X. T.; KOBAYASHI, T.; TODO, T.; IKEUCHI, T.; YOSHIURA, M.; KAJIURA-KOBAYASHI, H.; MORREY, C.; NAGAHAMA, Y. Molecular cloning of estrogen receptors $\mathrm{a}$ and $\mathrm{b}$ in the ovary of a teleost fish, the tilapia (Oreochromis niloticus). Zoological Science, Washington, v. 16, n. 4, p. 653-658, 1999.

CRUZ, E. M. V.; MAIR, G. C. Conditions for effective androgen sex reversal in Oreochromis niloticus $(\mathrm{L})$. Aquaculture, Amsterdam, v. 122, n. 2-3, p. 237-248, 1994.

DEVLIN, R. H.; NAGAHAMA, Y. Sex determination and sex differentiation in fish: an overview of genetic, physiological, and environmental influences. Aquaculture, Amsterdam, v. 208, n. 3-4, p. 191-364, 2002.

DORIZZI, M.; MIGNOT, T. M.; GUICHARD, A.; DESVAGES, G.; PIEAU, C. Involvement of oestrogens in sexual differentiation of gonads as a function of temperature in turtles. Differentiation, New York, v. 47, n. 1, p. 9-17, 1991.

GOLTERMAN, H. L.; CLYMO, R. S.; OHNSTAD, M. A. M. Methods for physical and chemical analysis of fresh waters. Oxford: Blackwell Scientific, 1978. 213 p.

GRAHAME-SMITH, D. G.; ARONSON, J. K. Tratado de farmacologia clínica e farmacoterapia. 3. ed. Rio de Janeiro: Guanabara Koogan, 2002. 640 p.

GUIGUEN, Y.; BAROILLER, J. F.; RICORDEL, M. J.; ISEKI, K.; McMEEL, O. M.; MARTIN, S. A. M.; FOSTIER, A. Involvement of estrogens in the process of sex differentiation in two fish species: the rainbow trout (Oncorhynchus mykiss) and a tilapia (Oreochromis niloticus). Molecular Reproduction and Devolopment, Great Britain, v. 54, n. 2, p. 154-162, 1999.

HAYES, T. B. Sex determination and primary sex differentiation in amphibians: Genetic and developmental mechanisms. Journal of Experimental Zoology, Autin, v. 281, n. 5, p. 373-399, 1998.

HINES, G. A.; WATTS, S. A. Nonsteroidal chemical sex manipulation of tilapia. Journal of the World Aquaculture Society, New Orleans, v. 26, n. 1, p. 98-102, 1995.
JOHNSTONE, R.; MACINTOSH, D. J.; WRIGHT, R. S. Elimination of orally administered 17 $\alpha$-methyltestosterone by Oreochromis mossambicus (Tilapia) and Salmogardneri (Rainbow trout) juveniles. Aquaculture, Amsterdam, v. 35, p. 249-257, 1983.

JORDAN, V. C.; DIX, C. J.; ROWSBY, L.; PRESTWICH, G. Studies on the mechanism of action of the non steroid alantio estrogen tamoxifen (I.C.I. 46,474) in the rat. Molecular and Cellular Endocrinology, New York, v. 7, n. 2, p. 177-192, 1977.

KITANO, T.; KOYANAGI, T.; ADACHI, R.; SAKIMURA, N.; TAKAMUNE, K.; ABE, S. I. Assessment of estrogenic chemicals using an estrogen receptor a $(E R \alpha)$ - and $E R \beta$ - mediated reporter gene assay in fish. Marine Biology, New York, v. 149, n. 1, p. 49-55, 2006.

KITANO, T.; YOSHINAGA, N.; SHIRAISHI, E.; KOYANAGI, T.; ABE, S. I. A tamoxifen induces masculinization of genetic females and regulates P450 aromatase and müllerian inhibiting substance mRNA expression in Japanese flounder (Paralichthys olivaceus). Molecular Reproduction and Development, New York, v. 74, n. 9, p. 1171-1177, 2007.

KOO, G. C.; ALLEN, H. L.; LONG, R. A.; SERIODUNN, R.; GOGGIN, B.; WEPPELMAN, R. M. Effect of tamoxifen on $\mathrm{H}-\mathrm{Y}$ antigen expression and gonadal development in chicken embryos. Differentiation, New York, v. 29, n. 2, p. 140-144, 1985.

MATTHEWS, J.; GUSTAFSSON, J. A. Estrogen signaling: a subtle balance between ER $\alpha$ and ER $\beta$. Molecular Intervention, Amstrerdam, v. 3, p. 281-292, 2003.

MIYATA, S.; KUBO, T. In vitro effects of estradiol and aromatase inhibitor treatment on sex differentiation in Xenopuslaevis gonads. General and Comparative Endocrinology, London, v. 119, n. 1, p. 105-110, 2000.

MUELLER, S. O.; KORACH, K. S. Mechanisms of estrogen receptor-mediated agonistic and antagonistic effects. In: METSLER, M. The handbook of environmental chemistry. Part I, Berlin: Springer-Verlag, v. 3, part 1, 2001. p. 12-25.

NAGAHAMA, Y. Molecular mechanisms of sex determination and gonadal sex differentiation in fish. Fish Physiology and Biochemistry, Amsterdam, v. 31, n. 2, p. 105-109, 2005.

NAKAMURA, M.; BHANDARI, R. K.; HIGA, M. The role estrogens play in sex differentiation and sex changes of fish. Fish Physiology and Biochemistry, Amsterdam, v. 28, n. 1-4, p. 113-117, 2003. 
NAVARRO-MARTIN, L.; BLÁQUEZ, M.; PIFERRER, F. Masculinization of the European sea bass (Dicentrarchuslabrax) by treatment with an androgen or aromatase inhibitor involves different gene expression and has distinct lasting effects on maturation. General and Comparative Endocrinology, London, v. 160, n. 1, p. 3-11, 2009.

OSBORNE, C. K.; ELLEDGE, R. M.; FUQUA, S. A. W. Estrogen receptors in breast cancer therapy. Science \& Medicine, Philadelphia, v. 3, n. 1, p. 32-41, 1996.

PHELPS, R. P.; POPMA, T. J. Sex reversal of tilapia In: COSTA PIERCE, B. A.; RAKOCY, J. E. (Ed.). Tilapia aquaculture in the Americas. Louisiana: World Aquaculture Society, v. 2, 2000. p. 34-59.

PIEAU, C.; DORIZZI, M. Oestrogens and temperature dependent sex determination in reptiles: all is in the gonads. Journal of Endocrinology, Quebec, v. 181, n. 3, p. 367-377, 2004.

PIFERRER, F. Endocrine sex control strategies for the feminization of teleost fish. Aquaculture, Amsterdam, v. 197, n. 1-4, p. 229-281, 2001.

PIFERRER, F.; GUIGUEN, Y. Fish gonadogenesis. Part 2. molecular biology and genomics of fish sex differentiation. Reviews Fisheries Science, Amsterdam, v. 16, n. 1, p. 33-53, 2008.

POPMA, T. J.; LOVSHIN, L. Worldwide prospects for commercial production of tilapia. Auburn: Auburn University, 1996. (Research and development, 41).

POPMA, T. J.; GREEN, B. W. Sex reversal of tilapia in earthen ponds: aquaculture production manual. Alabama: Auburn University, 1990. (Research and development series, 35).
SHARPE, R. L.; MACLATCHY, D. L.; COURTENAY, S. C.; VAN DER KRAAK, G. J. Effects of a model androgen (methyltestosterone) and a model antiandrogen (cyproterone acetate) on reproductive endocrine endpoints in short-term adult mummichog (Fundulusheteroclitus). Aquatic Toxicology, Oxford, v. 67, n. 3, p. 203-215, 2004.

SMITH, C. A.; SINCLAR, A. H. Sex determination: insights from the chicken. BioEssays, Cambridge, v. 26, n. 2, p. 120-132, 2004.

SOCORRO, S.; POWER, D. M.; OLSSON, P. E.; CANARIO, A. V. M. Two estrogen receptors expressed in the teleost fish, Sparusaurata: cDNA cloning, characterization and tissue distribution. Journal Endocrinology, Quebec, v. 166, n. 2, p. 293-306, 2000.

VOLPATO, G. L.; FRIOLI, P. M. A.; CARRIERI, M. P. Heterogeneous growth in fish: some data in the Nile tilapia Oreochromisniloticusand a general view about the casual mechanisms. Boletim de Fisiologia Animal, São Paulo, v. 13, n. 2, p. 7-22, 1989.

XIA, Z.; GALE, W. L.; CHANG, X.; LANGENAU, D.; PATIÑO, R.; MAULE, A. G. DENSMORE, L. D. Phylogenetic sequence analysis, recombinant expression, and tissue distribution of a channel catfish estrogen receptor $\beta$. General and Comparative Endocrinology, London, v. 118, n. 1, p. 139-149, 2000.

XIA, Z.; PATIÑO, R.; GALE, W.L.; MAULE, A. G.; DENSMORE, L. D. Cloning, in vitro expression, and novel phylogenetic classification of a channel catfish estrogen receptor. General and Comparative Endocrinology, London, v. 113, n. 3, p. 360-368, 1999.

ZANARDI, M. F.; DIAS KOBERSTEIN, T. C. R.; URBINATI, E. C.; FAGUNDES, M.; SANTOS, M. A. dos; MATAQUEIRO, M. I. Concentrações de hormônio na carcaça de tilápias-do-nilo e maturação precoce após reversão sexual. Revista Brasileira de Zootecnia, Viçosa, MG, v. 40, n. 1, p. 7-11, 2011. 